\title{
Discovery of potent telomerase activators: Unfolding new therapeutic and anti-aging perspectives
}

\author{
DIMITRIS TSOUKALAS ${ }^{1-3^{*}}$, PERSEFONI FRAGKIADAKI ${ }^{3,4 *}$, ANCA OANA DOCEA $^{5^{*}}$, \\ ATHANASIOS K. ALEGAKIS ${ }^{3}$, EVANGELIA SARANDI ${ }^{1,3}$, MARIA THANASOULA ${ }^{1}$, DEMETRIOS A. SPANDIDOS ${ }^{6}$, \\ ARISTIDIS TSATSAKIS ${ }^{3,4}$, MAYYA PETROVNA RAZGONOVA ${ }^{7}$ and DANIELA CALINA ${ }^{2}$ \\ ${ }^{1}$ Metabolomic Medicine, Health Clinics for Autoimmune and Chronic Diseases, 10674 Athens, Greece; \\ ${ }^{2}$ Department of Clinical Pharmacy, University of Medicine and Pharmacy, Faculty of Pharmacy, 200349 Craiova, Romania; \\ ${ }^{3}$ Laboratory of Toxicology, Medical School, University of Crete, 71003 Heraklion; ${ }^{4}$ Spin-Off Toxplus S.A., \\ 71601 Heraklion, Greece; ${ }^{5}$ Department of Toxicology, University of Medicine and Pharmacy, Faculty of Pharmacy, \\ 200349 Craiova, Romania; ${ }^{6}$ Laboratory of Clinical Virology, School of Medicine, University of Crete, \\ 71003 Heraklion, Greece; ${ }^{7}$ SEC Nanotechnology, Far Eastern Federal University, Vladivostok 690950, Russia
}

Received April 8, 2019; Accepted August 9, 2019

DOI: $10.3892 / \mathrm{mmr} .2019 .10614$

\begin{abstract}
Telomere length, a marker of cellular aging, decreases with age and it has been associated with aging-related diseases. Environmental factors, including diet and lifestyle factors, affect the rate of telomere shortening which can be reversed by telomerase. Telomerase activation by natural molecules has been suggested to be an anti-aging modulator that can play a role in the treatment of aging-related diseases. This study aimed to investigate the effect of natural compounds on telomerase activity in human peripheral blood mononuclear cells (PBMCs). The tested compounds included Centella asiatica extract formulation (08AGTLF), Astragalus extract formulation (Nutrient 4), TA-65 (containing Astragalus membranaceus extract), oleanolic acid (OA), maslinic acid (MA), and 3 multi-nutrient formulas (Nutrients 1, 2 and 3) at various concentrations. The mean absorbance values of telomerase activity measured following
\end{abstract}

Correspondence to: Professor Aristidis Tsatsakis, Laboratory of Toxicology, Medical School, University of Crete, P.O. Box 1393, 71003 Heraklion, Greece

E-mail: tsatsaka@med.uoc.gr

*Contributed equally

Abbreviations: CAD, cardiovascular disease; BMI, body mass index; TLDP, telomere length database project; COPD, chronic obstructive pulmonary disease; TERT, transcriptase catalytic subunit; TERC, telomerase RNA component; DKC, Dyskeratosis congenita; 08AGTLF, Centella asiatica extract formulation; MA, maslinic acid; OA, oleanolic acid; PBMCs, peripheral blood mononuclear cells; CAG, cycloastragenol

Key words: telomerase activity, natural molecules, telomere length, PBMCs treatment with some of the above-mentioned formulations were statistically significantly higher compared to those of the untreated cells. In particular, in order of importance with respect to telomerase activation from highest to lowest, 08AGTLF, OA, Nutrient 4, TA-65, MA, Nutrient 3 and Nutrient 2, triggered statistically significant increase in telomerase activity compared to the untreated cells. 08AGTLF reached the highest levels of telomerase activity reported to date, at least to our knowledge, increasing telomerase activity by 8.8 folds compared to untreated cells, while Nutrient 4 and OA were also potent activators (4.3-fold and 5.9-fold increase, respectively). On the whole, this study indicates that the synergistic effect of nutrients and natural compounds can activate telomerase and produce more potent formulations. Human clinical studies using these formulations are required to evaluate their mode of action. This would reveal the health benefits of telomerase activation through natural molecules and would shed new light onto the treatment of aging-related diseases.

\section{Introduction}

Several studies have indicated that short telomere length is associated with aging-related diseases, including cardiovascular diseases (CADs), stroke, cancer, arthritis, osteoporosis, cataracts, diabetes type 2 , hypertension, mental diseases, chronic obstructive pulmonary disease (COPD) and dementia (1). Telomere shortening can be affected by environmental factors, including physical activity, body mass index (BMI), hormone replacement therapy, smoking, chronic inflammation, oxidative stress, dietary antioxidants and vitamins (2-5). For instance, DNA-damage caused by various environmental factors triggers a DNA-damage response at telomeres that protects them from instability and shortening (6,7). Moreover, Vakonaki et al demonstrated an association between telomere length and drug abuse, which leads to premature biological aging (8). Telomere length has been proposed to be a biomarker of somatic cell aging, while the rate of increase of short telomeres has been 
linked to longevity in mammals (9). Indeed, when the length of the telomeres shortens below a threshold limit, cell growth is restricted and cells undergo cellular senescence or apoptosis (10). In a recent study, it was found that the administration of nutraceutical supplements may be linked to sustaining the telomere length in healthy adults (11). To determine the rate of telomere shortening and increase in the percentage of short telomeres with aging, we generated 'BIOTEL version 2.4' that was validated using data from Telomere Length Database Project (TLDP) (12), and allows the easy production of graphs and track telomere shortening in response to stimuli.

The shortening of telomeres can be reversed by the enzyme telomerase, which is active in high-proliferating cells, such as in male germ cells, activated lymphocytes, stem cells and cancer cells $(13,14)$. It consists of two domains, namely a reverse transcriptase catalytic subunit (TERT) and an associated telomerase RNA component (TERC) (15). However, the majority of adult human somatic cells are telomerase-deficient and their proliferation contributes to progressive telomere shortening with age, ultimately leading to aging and death(16). In addition, telomerase-related gene mutations result in the development of certain diseases, such as Dyskeratosis Congenita (DKC) that is the first disease to be associated with mutations in human telomerase gene (17). Telomerase mutations have also been detected in aplastic anemia, Hoyeraal-Hreidarsson syndrome and idiopathic pulmonary fibrosis, while numerous epidemiological studies have demonstrated that telomerase activity is associated with pregnancy complications $(18,19)$ and mental disorders $(20)$. Thus, based on all the above, telomerase activators may be potent agents in anti-aging and in the treatment of telomerase-dependent diseases. It has been further demonstrated that telomerase activators enhance the efficiency of the DNA repair process and protect cells from stress and DNA-damaging conditions (21). Telomerase activation has been achieved through natural molecules, synthetic molecules and genetic manipulation and intervention (22). Several extracts from the Astragalus membranaceus root have been studied as possible telomerase activators (22-26). Such an extract is TA-65, a natural product telomerase activator marketed since 2008, that has been found to lengthen telomeres in humans (23). A previous in vitro study on human CD4 and CD8 T-cells suggested that cycloastragenol (CAG), a triterpenoid saponin compound obtained from Astragaloside IV hydrolysis that is the main compound in Astragalus, increased telomerase activity and reduced the effects of aging (24). Product B, a herb nutraceutical that contains 'telomere support' compounds and antioxidants, has also been suggested to be a potent telomerase activator, although no long-term test data are currently available.

The aim of the present study was to test supplements and natural extracts for their capacity to enhance telomerase activity in human peripheral blood mononuclear cells (PBMCs). We demonstrate that Centella asiatica extract formulation (08AGTLF) can lead to significantly higher telomerase activation compared to untreated cells, as well as TA-65 and other supplements containing Astragalus extract and CAG. This is the first study, at least to our knowledge, to demonstrate that a natural formulation, such as Centella asiatica extract formulation (08AGTLF) can lead to such high telomerase activity relative to control cells.

\section{Materials and methods}

Formulations. Centella asiatica extract formulation (08AGTLF) which consisted of $>95 \%$ high-purity triterpenes was obtained from ApexBio Company. Oleanolic acid (OA) was obtained from Sigma-Aldrich and maslinic acid (MA) was obtained from Extrasynthese. Nutrient 1 and Nutrient 2 (contents shown below) were obtained from Lumis Research S.A. Nutrient 3 and Nutrient 4 (contents shown below) were obtained from Natural Doctor S.A. Each compound was dissolved in ethanol to achieve various concentrations to be tested in the cell cultures.

Cell isolation and telomerase activity measurements. The protocol of this study was approved by the Ethics Committee for Patients and Biological Material of the University of Crete with reference no. 63/22.03.2019. All procedures performed involving human participants were carried out under the ethical standards of the 1964 Helsinki declaration and its later amendments, or comparable ethical standards. The study was performed using samples prepared from healthy donors that volunteered to participate in the study. The samples were anonymized and personal data were managed according to the EU General Data Protection Regulation (GDPR).

PBMCs where isolated from the blood samples by Ficoll-Hypaque gradient centrifugation. The cells were grown in DMEM (Biochrom AG; F0455) supplemented with $10 \%$ fetal bovine serum (FBS; 10500-064, heat-inactivated; Invitrogen; Thermo Fisher Scientific), glutamine (4 mM; Biosera XCT1715), gentamycin (15710-049; Invitrogen; Thermo Fisher Scientific) and penicillin/streptomycin (100 U/ml; Biosera LMA4118). Prior to the addition of the test agents, the cells were cultured in serum-free medium for $24 \mathrm{~h}$ at $37^{\circ} \mathrm{C}$ and $5 \% \mathrm{CO}_{2}$. The PBMCs were then treated with the compounds at various concentrations, for 24-72 h. PBMCs samples were collected at 24-72 h following treatment, washed in PBS buffer and stored at $-80^{\circ} \mathrm{C}$. Telomerase activity was measured using a commercial telomerase PCR-ELISA (Sigma-Aldrich), based on the telomeric repeat amplification protocol, as previously described (27-30). All treatments for each condition were performed in triplicates.

Contents of Nutrients 1, 2, 3 and 4. Nutrient 1 (My Shape) contained the following: Alpha lipoic acid, cinnamon) bark dry extract 1/4 (Cinnamomum zeylanycum N.), magnesium citrate, L-glutamine, L-carnitine tartrate, potassium citrate, ascorbic acid, magnesium ascorbate, green tea (Camellia sinensis K.) leaves dry extract titrated to $95 \%$ polyphenols, natural vitamin $\mathrm{E}$ acetate $50 \%$, enzimix (amylase, protease, glucose amilase, lipase, cellulase, lactase, pectinase), niacin, bitamin B1, vitamin K2 Mena Q7 0.2\%, selenium methionine, vitamin B2, $\beta$-carotene, vitamin B5, choline bitartrate, inositol, para-aminobenzoic acid (PABA), vitamin B6, vitamin B12 1\%, chromium picolinate, vitamin D3 2.5\%, biotin, folic acid, anti-caking agent (cellulose, mono- and diglycerides of fatty acid, magnesium stearate, silica dioxide).

Nutrient 2 (My Health) contained the following: Mix Vitamin (ascorbic acid, vitamin E acetate 50\% natural, niacin, vitamin B1, vitamin K2 Mena Q7 0.2\%, vitamin B6, $\beta$-carotene, vitamin B12 1\%), anti-caking agents (microcrystalline 
cellulose, mono- and diglycerides of fatty acids, magnesium stearate, silica dioxide).

Nutrient 3 (Vit. D3\&K2 Cofactors, 1 capsule) contained the following: 2,000 $\mathrm{OH}_{25} \mathrm{D}_{3}, 100 \mu \mathrm{g}$ vitamin $\mathrm{K} 2$ (MK7), $56 \mathrm{mg}$ elemental magnesium as magnesium bisglycinate.

Nutrient 4 (REYOUTH, 1 capsule) contained the following: Vitamin C (50 mg), Magnesium (58 mg), CAG (16 mg) and amino-acids mix containing L-glutamine, L-lysine, L-proline, L-glycine, L-arginine, L-leucine, L-histidine, L-isoleucine, L-valine, L-methionine, L-tyrosine, glutamic acid, L-phenylalanine, L-serine, L-threonine, L-alanine, L-citrulline, L-taurine, L-tryptophan, aspartic acid, Vitamin E (12 mg), calcium, Vitamin B3, Broccoli dry extract, dry fruit and vegetable extract, blend of digestive enzymes (Enzymix), potassium, Vitamin B1, Zinc, Vitamin B6, manganese, phosphorus, B-carotene, Vitamin B5, inositol, Vitamin K2, Vitamin B2, PABA, Vitamin D3, biotin, chromium, copper, selenium, molybdenum, Vitamin B12.

TA-65 (1 capsule) contained the following: Astragalus membranaceus moench extract (TA- $65^{\circledR} \mathrm{MD}, 8 \mathrm{mg}$ ).

Statistical analysis. The mean (xm), standard deviation (SD) and the estimated approximated 95\% confidence interval $(95 \% \mathrm{CI})(\mathrm{xm} \pm 1.96 \mathrm{SD} / \sqrt{ } \mathrm{n}$ (where $\mathrm{n}-\mathrm{n}=3$ - was the number of replications) of the absorbance values were applied. All experiments were performed in triplicates and the mean values were used for the data presentation of differences of telomerase activity triggered by each formulation vs. the control, expressed as P-values resulting from one-way ANOVA followed by Dunnett's post-hoc test for pairwise comparisons with untreated cells. All statistical analyses were performed in IBM SPSS Statistics 24.0 and diagrams were created using Excel 365 for Windows (Microsoft Corp.) and a value of $\mathrm{P}<0.05$ was considered to indicate a statistically significant difference.

\section{Results}

A summary of the compounds used and the calculated concentrations $(\mu \mathrm{g} / \mathrm{ml})$ in vitro is presented in Table I. Fig. 1 depicts the mean values of the telomerase activity (expressed in absorbance units, $\left.A_{450 \mathrm{~nm}}-\mathrm{A}_{690 \mathrm{~nm}}\right)$ of cells treated with the formulations and compounds (08AGTLF, TA-65, Nutrient 4, $\mathrm{OA}$ and MA) in comparison with the ethanol-only treated cells, hereafter referred as untreated cells. Importantly, all the compounds tested were not toxic for the cells, as they only led to small amount of apoptosis or necrosis (13-15\%), similar with the untreated cells (13\%; data not shown). 08AGTLF exhibited the highest telomerase activity, 1.35 absorbance units (95\% CI, 1.154-1.546) at the concentration of $0.02 \mu \mathrm{g} / \mathrm{ml}$ and $1.18(95 \% \mathrm{CI}, 1.088-1.278)$ at the concentration of $0.2 \mu \mathrm{g} / \mathrm{ml}$, while it decreased at the concentration of $2 \mu \mathrm{g} / \mathrm{ml}$. The difference in telomerase activity reached the levels of 8.8 -fold increase relative to the untreated cells at the concentration of $0.02 \mu \mathrm{g} / \mathrm{ml}$. Importantly, the differences in telomerase activity of the treated cells compared to the untreated ones were statistically significant with P-values $<0.001$ and $<0.0001$ for the 0.02 and $0.2 \mu \mathrm{g} / \mathrm{ml}$ concentrations, respectively.

Telomerase activity levels increased with all the 3 concentrations used for Nutrient 4 compared to the untreated
Table I. Concentrations in $\mu \mathrm{g} / \mathrm{ml}$ of all the formulations and compounds used for measuring telomerase activity in PBMCs.

\begin{tabular}{lc} 
Nutrients & Concentration $(\mu \mathrm{g} / \mathrm{m} /)$ \\
\hline Nutrient 1 & $20,120,600$ \\
Nutrient 2 & $10,60,330$ \\
Nutrient 3 & $4,20,100$ \\
Nutrient 4 & $12.8,25,51$ \\
08AGTLF & $0.02,0.2,2$ \\
TA-65 & $0.16,0.32,0.64$ \\
OA & $1,5,10$ \\
MA & $1,5,10$
\end{tabular}

PBMCs, peripheral blood mononuclear cells; 08AGTLF, Centella asiatica extract formulation; MA, maslinic acid; OA, oleanolic acid.

cells (up to 4.3-fold increase) with the highest activation at the concentration of $12.8 \mu \mathrm{g} / \mathrm{ml}$ (absorbance $0.38 ; 95 \% \mathrm{CI}$, 0.311-0.456) and followed a slightly decreasing pattern at the concentrations of 25 and $51 \mu \mathrm{g} / \mathrm{ml}$ (95\% CI, 0.321-0.426 and $0.320-0.414$, respectively). In addition, the difference in telomerase activity relative to the untreated cells were all statistically significant, with $\mathrm{P}<0.01$ for the concentration of $12.8 \mu \mathrm{g} / \mathrm{ml}$ and $\mathrm{P}<0.001$ for the concentrations of 25 and $52 \mu \mathrm{g} / \mathrm{ml}$ (Fig. 1).

Treatment with TA-65 also exhibited telomerase activation compared to the untreated cells (approximately 2-fold increase). The highest values were acquired at the concentration of 0.16 and $0.32 \mu \mathrm{g} / \mathrm{ml}$ (95\% CI, 0.197-0.210 and 0.190-0.203, respectively), while there was also a small activation at the concentration of $0.64 \mu \mathrm{g} / \mathrm{ml}$ (95\% CI, 0.155-0.182). Importantly, differences in telomerase activity compared to the untreated cells were statistically significant in all the 3 concentrations $(\mathrm{P}<0.001$; Fig 1$)$.

$\mathrm{OA}$ and MA triggered higher levels of telomerase activation at the concentrations of 1 and $10 \mu \mathrm{g} / \mathrm{ml}$, respectively. Telomerase activation was significantly higher, approximately 6-fold, at $1 \mu \mathrm{g} / \mathrm{ml}$ of OA treatment (95\% CI, 0.391-0.549) and approximately 2 -fold higher at $10 \mu \mathrm{g} / \mathrm{ml}$ of MA treatment (95\% CI, 0.197-0.210), compared to the untreated cells. The increase in telomerase activity was statistically significant for the treatments with 1 and $5 \mu \mathrm{g} / \mathrm{ml}$ for $\mathrm{OA}$ with $\mathrm{P}<0.001$ and $\mathrm{P}<0.01$, respectively, and $10 \mu \mathrm{g} / \mathrm{ml}$ for MA with $\mathrm{P}<0.001$.

Fig. 2 depicts telomerase activity measured in absorbance units in the cells treated with Nutrient 1, Nutrient 2 and Nutrient 3 compared with the untreated cells. Telomerase activity triggered by Nutrient 1 did not differ significantly compared to the untreated cells at any of the concentrations used $(20,120$ and $600 \mu \mathrm{g} / \mathrm{ml})$ and the P-values for the difference in telomerase activity at the same concentrations compared to the untreated were higher than 0.05 . Nutrient 2 triggered a 1.5-fold increase in telomerase activity (95\% CI, 0.119-0.154) that was statistically significant at the concentration of $330 \mu \mathrm{g} / \mathrm{ml}$ $(\mathrm{P}<0.05)$, but not at the other 2 concentrations used $(10$ and $60 \mu \mathrm{g} / \mathrm{ml})$ that remained at levels similar with the untreated cells with P-values higher than 0.05. Finally, Nutrient 3 exerted a greater effect on telomerase activity (95\% CI, 0.157-0.203) at the concentration of $100 \mu \mathrm{g} / \mathrm{ml}$ relative to the untreated that 


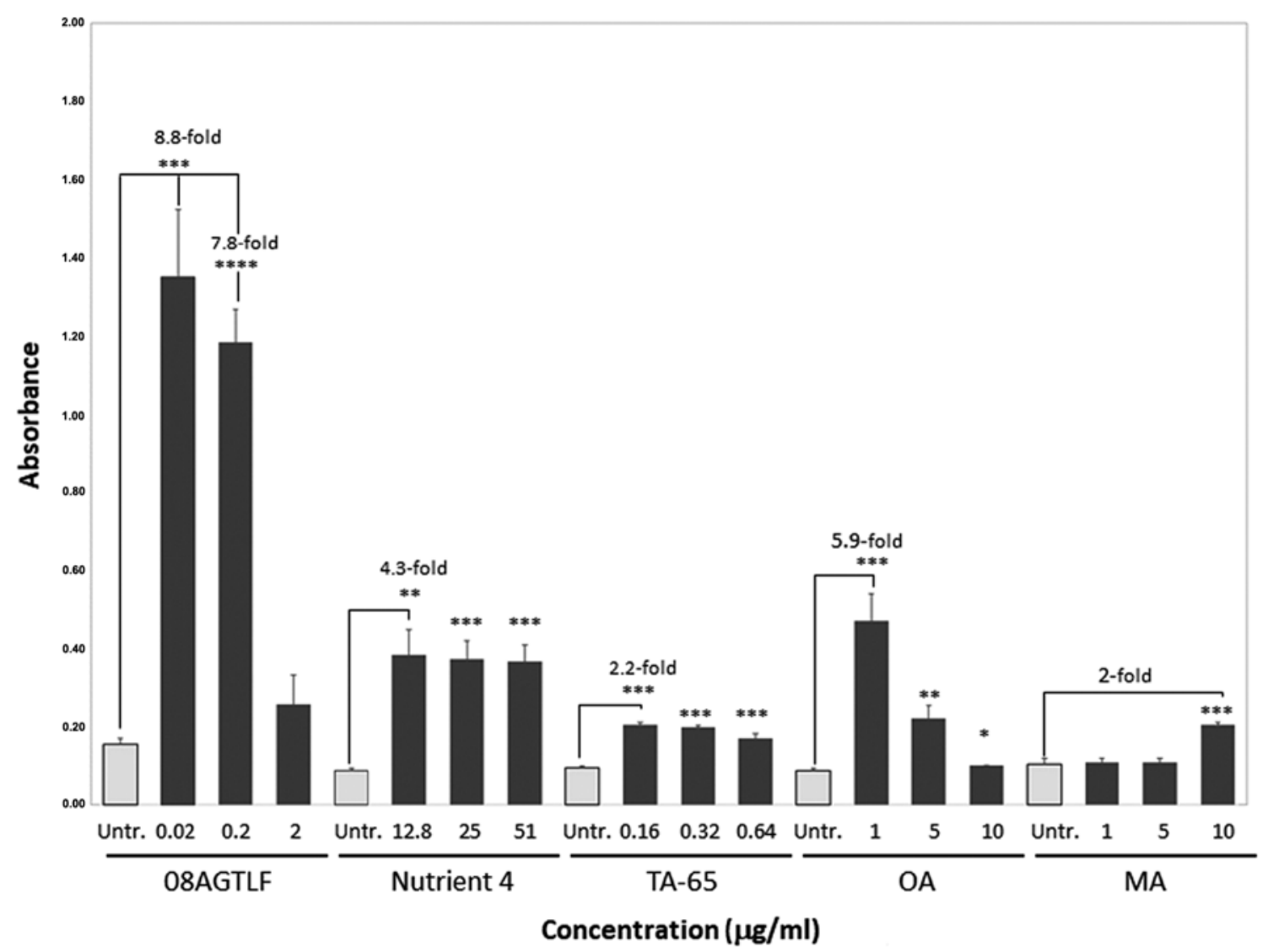

Figure 1. Telomerase activity expressed in absorbance units $\left(\mathrm{A}_{450 \mathrm{~nm}}-\mathrm{A}_{690 \mathrm{~nm}}\right)$ in the untreated cells or after treatment of PBMCs with 08AGTLF (Centella asiatica extract folmulation), Nutrient 4, TA-65, OA (oleanolic acid) and MA (maslinic acid). Error bars represent the standard deviation of the mean. Each mean was estimated from triplicate experiments. Asterisks indicate significant differences in the mean absorbance values measured after treatment with each activator compared with untreated cells $\left({ }^{*} \mathrm{P}<0.05,{ }^{* *} \mathrm{P}<0.01,{ }^{* * *} \mathrm{P}<0.001\right.$ and $\left.{ }^{* * * *} \mathrm{P}<0.0001\right)$ at the indicated concentrations.

was statistically significant $(\mathrm{P}<0.01)$, but not at the concentrations of 4 and $20 \mu \mathrm{g} / \mathrm{ml}$ which had values similar to the untreated cells $(\mathrm{P}>0.05)$.

The increase in telomerase activity triggered in PBMCs treated with the natural activators can be also expressed as telomerase activation relative to the positive control that is usually telomerase activity in a cancer cell line. In this study, the positive control was HeLa extract telomerase activity that corresponded to an absorbance value of 7.8. It is common to measure telomerase activation in a cell line relative to a cancer cell line telomerase activity that reaches very high levels, in order to show the potency of an activator (according to the telomerase PCR-ELISA kit instructions). According to our results, following treatment with 08AGTLF, telomerase activity reached the $17.3 \%$ of the positive control, while after treatment with Nutrient 4 and TA-65 it reached the 5.5 and $2.6 \%$ of the positive control, respectively (Fig. 3).

\section{Discussion}

Telomerase activators are important for anti-aging and telomerase-dependent disease treatments, since telomere shortening has been associated with cellular aging and telomerase-related gene mutations with several diseases (31). In the current study, we characterized the effects of 08AGTLF, TA-65, MA, OA, and Nutrients 1, 2, 3 and 4 for their ability to induce telomerase activity in PBMCs. The active constituents of 08AGTLF,
TA-65, OA and MA include pentacyclic triterpene derivatives. Herein, we demonstrate that 08AGTLF, Nutrient 4, TA-65, $\mathrm{OA}$ and MA trigger different levels of telomerase activation with the most potent of the compounds being the formulation containing 08AGTL at $0.02 \mu \mathrm{g} / \mathrm{ml}$ concentration (1.35).

We demonstrated that 08AGTL formulation containing Centella asiatica extract was able to trigger an almost 9-fold increase in telomerase activity compared to the untreated cells, much higher than the rest of the compounds used in this study, suggesting that it could be a novel strong natural telomerase activator with important anti-aging effects. Centella asiatica is a widely used Ayurvedic medicine and traditional Chinese medicine, which has been shown to be effective in improving cognitive ability, increasing antioxidant response, as well as treating wound healing disturbances (32-34). In particular, Gray et al investigated the effect of Centella asiatica on cognitive ability, as well as mitochondrial and antioxidant response pathways in healthy mice. It was shown that treatment with Centella asiatica enhanced cognitive ability in mice and led to higher expression of mitochondrial and antioxidant genes in the brain and liver, which could contribute to cognitive improvement (33). Moreover, it has been suggested that Centella asiatica can heal wounds due to the specific plant chemicals that it contains, known as triterpenoid saponins. Somboonwong et al reported the wound healing activities of sequential hexane, ethyl acetate, methanol and water extract of Centella asiatica in incision and partial-thickness burn 


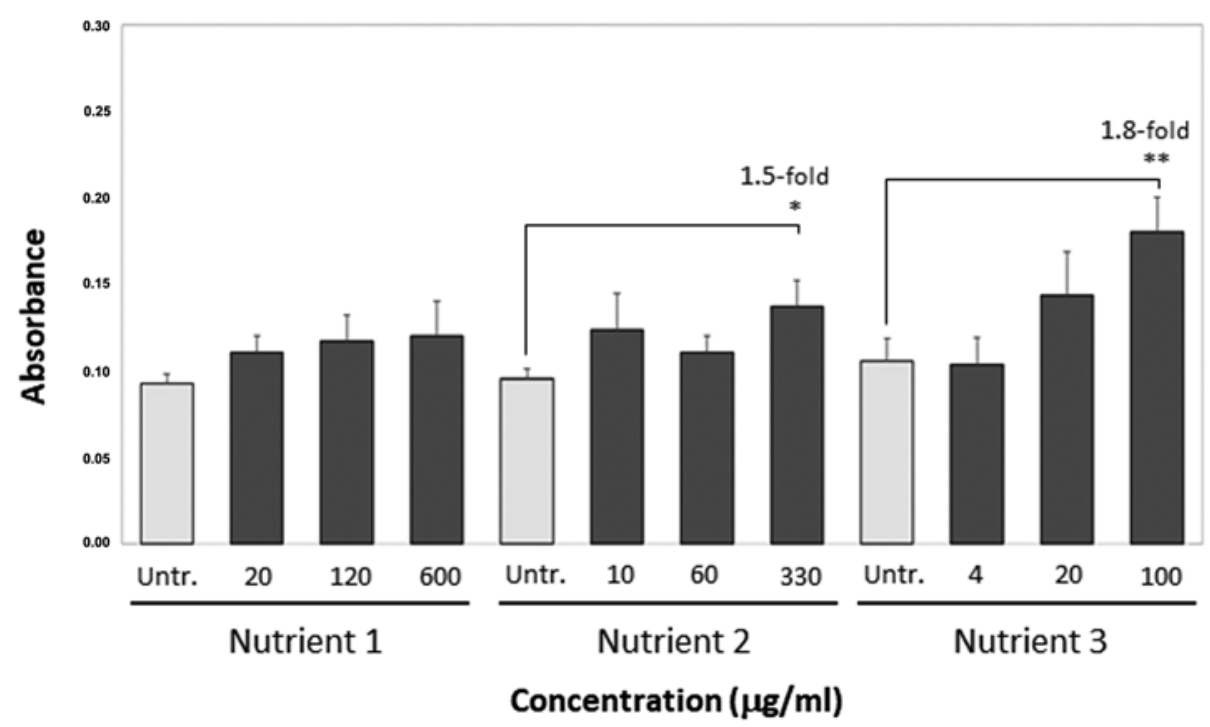

Figure 2. Telomerase activity expressed in absorbance units $\left(\mathrm{A}_{450 \mathrm{~nm}}-\mathrm{A}_{690 \mathrm{~nm}}\right)$ in the untreated cells or after treatment of PBMCs with 08AGTLF, Nutrient 1 , Nutrient 2 and Nutrient 3. Error bars represents the standard deviation of the mean. Each mean was estimated from triplicate experiments. Asterisks indicate significant differences in the mean absorbance values measured after treatment with each activator compared with untreated cells $\left({ }^{*} \mathrm{P}<0.05\right.$ and $\left.{ }^{* *} \mathrm{P}<0.01\right)$ at the indicated concentrations.

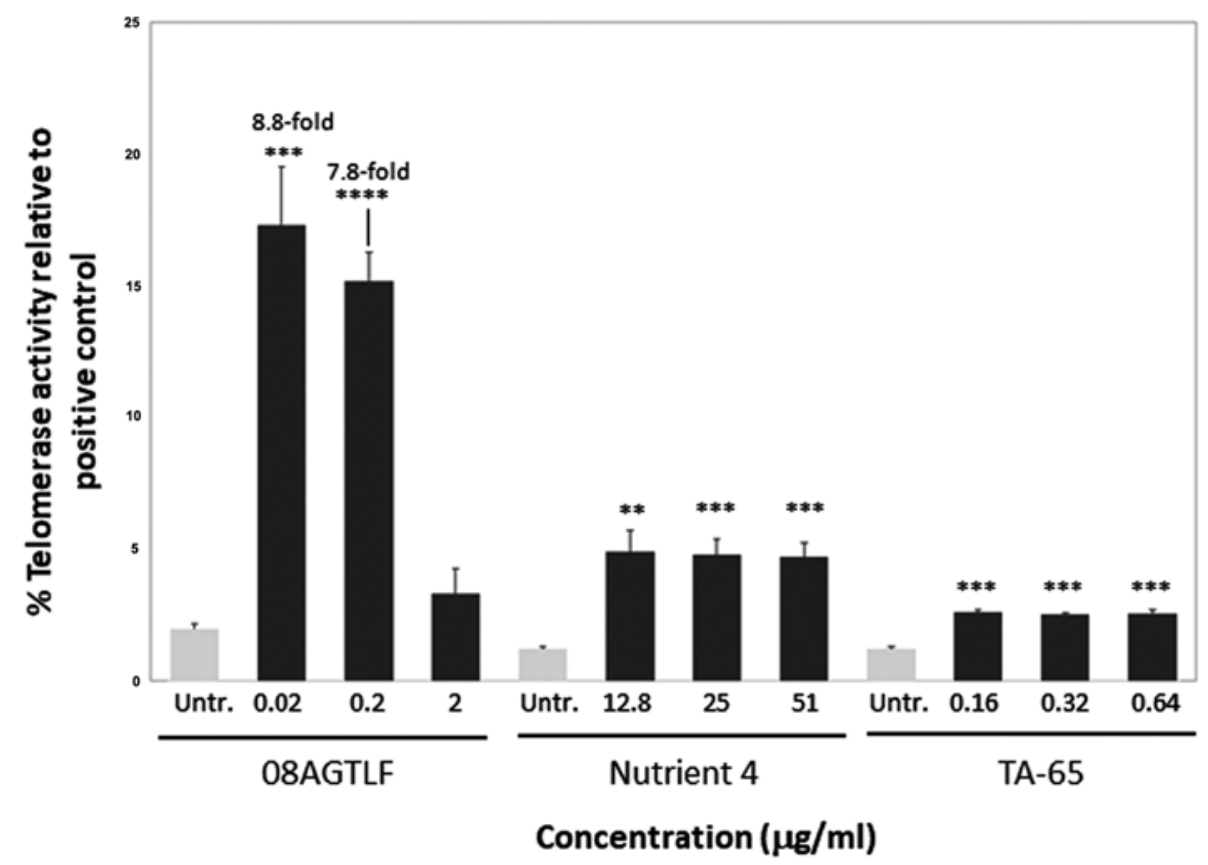

Figure 3. Telomerase activity expressed in \% relative to telomerase activity of the positive control (HeLa cell extract) for the untreated cells or after treatment with 08AGTLF, Nutrient 4 and TA-65. Error bars represents the standard deviation of the mean. Each mean was estimated from triplicate experiments. Asterisks indicate significant differences in the mean absorbance values measured after treatment with each activator compared with untreated cells $\left({ }^{* *} \mathrm{P}<0.01\right.$, ${ }^{* * *} \mathrm{P}<0.001$ and $\left.{ }^{* * * *} \mathrm{P}<0.0001\right)$ at the indicated concentrations.

wound models in rats. It was found that all extracts of Centella asiatica facilitated the wound healing process in both incisions and burn wounds due to the formulation inhibiting bacterial growth, fueling the growth of new skin cells and increasing skin 'tensile strength' and resilience (34).

Formulations that included Astragalus extract with different compositions (e.g. Nutrient 4 and TA-65) also exhibited statistically significant effect on telomerase activity, but much lower compared with 08AGTLF, reaching a 4.3-fold increase for Nutrient 4 and 2-fold increase for TA-65 relative to the untreated cells. In agreement with our results, Molgora et al demonstrated that TA-65 containing CAG, an algycone of Astragaloside IV, increased telomerase activity significantly 1.3 to 3.3 folds relative to controls in human T-cells cultures. Similarly, it has been shown that CAG activates telomerase both in vitro and in vivo (22). In particular, it has been shown that CAG activates telomerase and lengthens telomeres in a telomerase-dependent manner in vitro and decreases the percentage of critically short telomeres and DNA damage in the cell (35). 
Notably, Nutrient 4, a mixture of nutrients that contains CAG of Astragalus extract exhibited a higher effect on telomerase activity compared to TA-65 (4.3-fold increase), suggesting the synergistic effect of Astragalus extract with the other nutrients contained in Nutrient 4 . In a recent study by Bruno et al the authors examined the effects of a multivitamin supplement on telomere length and they suggested that telomerase activation mediated by this supplement resulted in higher telomere length (36).

Furthermore, we demonstrated that MA and OA were also potent activators of telomerase in specific concentrations, leading to a 5.9-fold and 2-fold increase in telomerase activity relative to the untreated, respectively. MA is a bioactive pentacyclic triterpenoid and has been associated with a low incidence of inflammation-related diseases (37). Fukumitsu et al demonstrated that MA, which was extracted from olive fruit, exerted an anti-inflammatory effect in humans. This study, that included middle-aged and elderly volunteers with mild knee joint pain, demonstrated that MA at the concentration of $50 \mathrm{mg} /$ day improved joint pain by promoting weight loss (37), while in another study, MA had a positive effect on the resistance to oxidative stress in animals (38). Moreover, Nur and Al-Jasabi determined the significant antioxidant properties of MA extracted from Plumeria rubra leaves, by performing quantitative and qualitative biochemical analysis (39). Similarly, OA is a pentacyclic triterpenoid widely found in plants, including fruits and vegetables that has been suggested to have a variety of pharmacological activities (40). However, very little is known about its effects on anti-aging. Zhang et al investigated whether OA has an effect on longevity in vivo in Caenorhabditis elegans and they showed that indeed OA could extend the lifespan by increasing resistance to stress and reducing the intracellular reactive oxygen species in wild-type worms (41). Another study evaluating the anti-wrinkle effects of OA, showed that not only it was innocuous to human skin fibroblasts, but could also significantly decrease the expression of both matrix metalloproteinase (MMP)-1 and MMP-2, and increase that of collagen type I alpha 1 chain (COL1A1), thus promoting collagen synthesis (42).

There are numerous studies that have associated nutraceutical supplementation with telomerase activity, telomere length and oxidative stress and it should be noted that natural products containing more than one antioxidant are more effective than the administration of a single one, suggesting a synergistic effect among these compounds $(43,44)$. In this study, we tested Nutrient 1 and Nutrient 2, which consist of a mix of vitamins and antioxidants and found that these supplements trigger a slight increase in telomerase activity. In agreement with this, Balcerczyk et al examined the effect of a diet supplement on parameters related to redox homeostasis and aging, and found that telomerase activity in PBMCs from healthy women, increased by $>25 \%$ (45). Surprisingly, Nutrient 3 , which contains vitamin $\mathrm{D}$, led to a significantly higher increase in telomerase activity (around 2-fold increase), when compared to the untreated cells. This finding is in accordance with the fact that vitamin D supplementation significantly increased PBMC telomerase activity in overweight African Americans, as shown by Zhu et al, suggesting that vitamin D may improve telomere maintenance, as well as prevent cell senescence and obesity-induced acceleration of cellular aging (46).
In conclusion, according to our in vitro model, an increase in telomerase activity between 2 to 9 folds compared with the untreated cells was observed with our tested molecules. Importantly the 08AGTL formulation containing Centella asiatica extract was the most potent activator among other commercially available supplements causing an almost 9-fold increase in telomerase activity at $0.02 \mu \mathrm{g} / \mathrm{ml}$. Moreover, the potency of 08AGTL in increasing telomerase activity was evident when translated in telomerase activation relative to the positive control, since it reached the $17.3 \%$ of the telomerase activity of the positive control, significantly higher percentage than the rest of the compounds tested (Fig. 3). The aim of this study was to identify natural compounds that significantly increase telomerase activation, and may lead to a longer life expectancy and healthy aging. 08AGTLF, containing Centella asiatica extract, seems to be such a natural compound with a strong effect on telomerase activity that remains to be validated with future research based on independent randomized controlled studies investigating the underlying mechanisms. Importantly, future intervention studies on humans are warranted to examine its effect on telomere length, aging and human health.

\section{Acknowledgements}

The study is part of the special part of the Ph.D. thesis from the University of Medicine and Pharmacy and Craiova. The authors would like to thank all the administrative, the technical and the medical staff of Toxplus S.A., the Metabolomic Medicine Health Clinic S.A., and the Laboratory of Toxicology for their dedicated involvement in this study.

\section{Funding}

This study was funded by Metabolomic Medicine S.A. and Toxplus S.A. and supported by the Special Research Account of University of Crete (ELKE nos. 4602, 4920 and 3963).

\section{Availability of data and materials}

The datasets presented in this study are available from the corresponding author upon reasonable request.

\section{Authors' contributions}

DT, PF, AT, DAS and DC conceived and designed the study and wrote the manuscript. MT, PF, MPR and ES performed the data processing and quality control assessment. AKA, AOD and MT performed the statistical analysis and data interpretation. All authors have reviewed and approved the manuscript before submission.

\section{Ethics approval and consent to participate}

The protocol of this study was approved by the Ethics Committee for Patients and Biological Material of the University of Crete with reference number 63/22.03.2019. Biological Material and information of patients were obtained with written informed consent according to the EU General Data Protection Regulation (GDPR). All procedures performed 
in studies involving human participants were under the ethical standards with the 1964 Helsinki declaration and its later amendments, or comparable ethical standards.

\section{Patient consent for publication}

Not applicable.

\section{Competing interests}

DAS is the Editor-in-Chief for the journal but had no personal involvement in the reviewing process, or any influence in terms of adjudicating on the final decision, for this article. DT is a scientific advisor for Lumis Research S.A. and Natural Doctor S.A. The remaining authors declare that they have no competing interests. To avoid any bias in the collection of the experimental data, the experiments were conducted by the Laboratory of Toxicology of the Medical School of the University of Crete. Lumis Research S.A. and Natural Doctor S.A. had no involvement in the preparation of the manuscript, the results and the supervision of the study.

\section{References}

1. Willeit P, Raschenberger J, Heydon EE, Tsimikas S, Haun M Mayr A, Weger S, Witztum JL, Butterworth AS, Willeit J, et al: Leucocyte telomere length and risk of type 2 diabetes mellitus: New prospective cohort study and literature-based meta-analysis. PLoS One 9: e112483-e112483, 2014.

2. Armanios M: Telomeres and age-related disease: How telomere biology informs clinical paradigms. J Clin Invest 123: 996-1002, 2013.

3. Pusceddu I, Herrmann M, Kirsch SH, Werner C, Hübner U, Bodis M, Laufs U, Wagenpfeil S, Geisel J and Herrmann W: Prospective study of telomere length and LINE-1 methylation in peripheral blood cells: The role of B vitamins supplementation. Eur J Nutr 55: 1863-1873, 2016.

4. Pusceddu I, Herrmann M, Kirsch SH, Werner C, Hübner U, Bodis M, Laufs U, Widmann T, Wagenpfeil S, Geisel J, et al One-carbon metabolites and telomere length in a prospective and randomized study of B- and/or D-vitamin supplementation. Eur J Nutr 56: 1887-1898, 2017.

5. Richards JB, Valdes AM, Gardner JP, Paximadas D, Kimura M, Nessa A, Lu X, Surdulescu GL, Swaminathan R, Spector TD, et al: Higher serum vitamin D concentrations are associated with longer leukocyte telomere length in women. Am J Clin Nutr 86: $1420-1425,2007$.

6. Thanasoula M, Escandell JM, Martinez P, Badie S, Muñoz P, Blasco MA and Tarsounas M: p53 prevents entry into mitosis with uncapped telomeres. Curr Biol 20: 521-526, 2010.

7. Thanasoula M, Escandell JM, Suwaki N and Tarsounas M: ATM/ ATR checkpoint activation downregulates CDC25C to prevent mitotic entry with uncapped telomeres. EMBO J 31: 3398-3410, 2012.

8. Vakonaki E, Tzatzarakis M, Tsiminikaki K, Nathena D, Fragkiadaki P, Kalliantasi K, Kanaki K, Vaki G, Plaitis S, Tsoukalas D, et al: Effect of chronic and heavy drug abuse on biological aging. World Acad Sci J 1: 67-73, 2019.

9. Vera E, Bernardes de Jesus B, Foronda M, Flores JM and Blasco MA: The rate of increase of short telomeres predicts longevity in mammals. Cell Rep 2: 732-737, 2012.

10. Shay JW and Wright WE: Hallmarks of telomeres in ageing research. J Pathol 211: 114-123, 2007.

11. Tsoukalas D, Fragkiadaki P, Docea AO, Alegakis AK, Sarandi E, Vakonaki E, Salataj E, Kouvidi E, Nikitovic D, Kovatsi L, et al: Association of nutraceutical supplements with longer telomere length. Int J Mol Med 44: 218-226, 2019.

12. Tsatsakis A,Tsoukalas D, Fragkiadaki P,VakonakiE,Tzatzarakis M, Sarandi E, Nikitovic D, Tsilimidos G and Alegakis AK: Developing BIOTEL: A semi-automated spreadsheet for estimating telomere length and biological age. Front Genet 10: 84, 2019.
13. Blackburn EH, Chan S, Chang J, Fulton TB, Krauskopf A, McEachern M,Prescott J, Roy J, Smith C and Wang H: Molecular manifestations and molecular determinants of telomere capping. Cold Spring Harb Symp Quant Biol 65: 253-263, 2000.

14. Beyne-Rauzy O, Prade-Houdellier N, Demur C, Recher C, Ayel J, Laurent G and Mansat-De Mas V: Tumor necrosis factor-alpha inhibits hTERT gene expression in human myeloid normal and leukemic cells. Blood 106: 3200-3205, 2005.

15. Blackburn EH: Switching and signaling at the telomere. Cell 106: 661-673, 2001.

16. Starkweather AR, Alhaeeri AA, Montpetit A, Brumelle J, Filler K, Montpetit M, Mohanraj L, Lyon DE and Jackson-Cook CK: An integrative review of factors associated with telomere length and implications for biobehavioral research. Nurs Res 63: 36-50, 2014.

17. Tárkányi I and Aradi J: Pharmacological intervention strategies for affecting telomerase activity: Future prospects to treat cancer and degenerative disease. Biochimie 90: 156-172, 2008.

18. Fragkiadaki P, Tsoukalas D, Fragkiadoulaki I, Psycharakis C, Nikitovic D and Spandidos D: and Tsatsakis A: Telomerase activity in pregnancy complications (Review). Mol Med Rep 14: 16-21, 2016

19. Vasilopoulos E, Fragkiadaki P, Kalliora C, Fragou D, Docea AO, Vakonaki E, Tsoukalas D, Calina D, Buga AM, Georgiadis G, et al: The association of female and male infertility with telomere length (Review). Int J Mol Med 44: 375-389, 2019.

20. Vakonaki E, Tsiminikaki K, Plaitis S, Fragkiadaki P, Tsoukalas D, Katsikantami I, Vaki G, Tzatzarakis MN, Spandidos DA and Tsatsakis AM: Common mental disorders and association with telomere length. Biomed Rep 8: 111-116, 2018.

21. Westin ER, Aykin-Burns N, Buckingham EM, Spitz DR, Goldman FD and Klingelhutz AJ: The p53/p21(WAF/CIP) pathway mediates oxidative stress and senescence in dyskeratosis congenita cells with telomerase insufficiency. Antioxid Redox Signal 14: 985-997, 2011.

22. Yu Y, Zhou L, Yang Y and Liu Y: Cycloastragenol: An exciting novel candidate for age-associated diseases. Exp Ther Med 16: 2175-2182, 2018. Review.

23. Bernardes de Jesus B, Schneeberger K, Vera E, Tejera A, Harley CB and Blasco MA: The telomerase activator TA-65 elongates short telomeres and increases health span of adult/old mice without increasing cancer incidence. Aging Cell 10: 604-621, 2011.

24. Fauce SR, Jamieson BD, Chin AC, Mitsuyasu RT, Parish ST, $\mathrm{Ng}$ HL, Kitchen CM, Yang OO, Harley CB and Effros RB: Telomerase-based pharmacologic enhancement of antiviral function of human $\mathrm{CD} 8^{+} \mathrm{T}$ lymphocytes. J Immunol 181: 7400-7406, 2008.

25. Harley CB, Liu W, Blasco M, Vera E, Andrews WH, Briggs LA and Raffaele JM: A natural product telomerase activator as part of a health maintenance program. Rejuvenation Res 14: 45-56, 2011.

26. Mutly AG: Telomerase inhibitors and activators: Pharmaceutical importance. In: Enzyme Inhibitors and Activators. Chapter 5. pp125-138, 2017.

27. Ozcagli E, Kara M, Kotil T, Fragkiadaki P, Tzatzarakis MN, Tsitsimpikou C, Stivaktakis PD, Tsoukalas D, Spandidos DA, Tsatsakis AM, et al: Stanozolol administration combined with exercise leads to decreased telomerase activity possibly associated with liver aging. Int J Mol Med 42: 405-413, 2018.

28. Kara M, Ozcagli E, Fragkiadaki P, Kotil T, Stivaktakis PD, Spandidos DA, Tsatsakis AM and Alpertunga B: Determination of DNA damage and telomerase activity in stanozolol-treated rats. Exp Ther Med 13: 614-618, 2017.

29. Zafiropoulos A, Tsarouhas K, Tsitsimpikou C, Fragkiadaki P, Germanakis I, Tsardi M, Maravgakis G, Goutzourelas N, Vasilaki F, Kouretas D, et al: Cardiotoxicity in rabbits after a low-level exposure to diazinon, propoxur, and chlorpyrifos. Hum Exp Toxicol 33: 1241-1252, 2014

30. Tsitsimpikou C, Tzatzarakis M, Fragkiadaki P, Kovatsi L, Stivaktakis P, Kalogeraki A, Kouretas D and Tsatsakis AM: Histopathological lesions, oxidative stress and genotoxic effects in liver and kidneys following long term exposure of rabbits to diazinon and propoxur. Toxicology 307: 109-114, 2013.

31. Holohan B, Wright WE and Shay JW: Cell biology of disease: Telomeropathies: An emerging spectrum disorder. J Cell Biol 205: 289-299, 2014.

32. Brinkhaus B, Lindner M, Schuppan D and Hahn EG: Chemical, pharmacological and clinical profile of the East Asian medical plant Centella asiatica. Phytomedicine 7: 427-448, 2000. 
33. Gray NE, Harris CJ, Quinn JF and Soumyanath A: Centella asiatica modulates antioxidant and mitochondrial pathways and improves cognitive function in mice. J Ethnopharmacol 180 : $78-86,2016$.

34. Somboonwong J, Kankaisre M, Tantisira B, and Tantisira MH: Wound healing activities of different extracts of Centella asiatica in incision and burn wound models: an experimental animal study. BMC Complement Altern Med: Jul 20, 2012 (Epub ahead of print). doi: 10.1186/1472-6882-12-103.

35. Molgora B, Bateman R, Sweeney G, Finger D, Dimler T, Effros RB and Valenzuela HF: Functional assessment of pharmacological telomerase activators in human T cells. Cells 2: 57-66, 2013.

36. Bruno EJ, Simpson GD and Martin RL: Extending telomere length with a multivitamin: A pilot study. J Health Educ Res Dev 5: 238, 2017.

37. Fukumitsu S, Villareal MO, Aida K, Hino A, Hori N, Isoda $H$ and Naito Y: Maslinic acid in olive fruit alleviates mild knee joint pain and improves quality of life by promoting weight loss in the elderly. J Clin Biochem Nutr 59: 220-225, 2016.

38. Montilla MP, Agil A, Navarro MC, Jiménez MI, GarcíaGranados A, Parra A and Cabo MM: Antioxidant activity of maslinic acid, a triterpene derivative obtained from Olea europaea. Planta Med 69: 472-474, 2003.

39. Nur NM and Al-Jasabi SM: Antioxidant properties of maslinic acid extracted from Plumeria Rubra leaves. IJCRR 8 20178-20183, 2017.

40. Ayeleso TB, Matumba MG and Mukwevho E: Oleanolic acid and its derivatives: Biological activities and therapeutic potential in chronic diseases. Molecules 22: 1915, 2017.

41. Zhang J, Lu L and Zhou L: Oleanolic acid activates daf-16 to increase lifespan in Caenorhabditis elegans. Biochem Biophys Res Commun 468: 843-849, 2015.
42. Hong YD, Yoo DS, Nam MH, Kim HC, Park SJ, Shin SS, Cheon JW and Park YH: Excellent anti-aging effects of ursolic acid and oleanolic acid present in Ligustrum lucidum. J Soc Cosmet Sci Korea 38: 181-187, 2012.

43. Bai H, Liu R, Chen HL, Zhang W, Wang X, Zhang XD, Li WL and Hai CX: Enhanced antioxidant effect of caffeic acid phenethyl ester and Trolox in combination against radiation induced-oxidative stress. Chem Biol Interact 207: 7-15, 2014

44. Stefanska B, Salamé P, Bednarek A and Fabianowska-Majewska K: Comparative effects of retinoic acid, vitamin $\mathrm{D}$ and resveratrol alone and in combination with adenosine analogues on methylation and expression of phosphatase and tensin homologue tumour suppressor gene in breast cancer cells. Br J Nutr 107: 781-790, 2012.

45. Balcerczyk A, Gajewska A, Macierzyńska-Piotrowska E, Pawelczyk T, Bartosz G, Szemraj J: Enhanced antioxidant capacity and anti-ageing biomarkers after diet micronutrient supplementation. Molecules 19: 14794-14808, 2014.

46. Zhu H, Guo D, Li K, Pedersen-White J, Stallmann-Jorgensen IS, Huang Y, Parikh S, Liu K and Dong Y: Increased telomerase activity and vitamin $\mathrm{D}$ supplementation in overweight African Americans. Int J Obes 36: 805-809, 2012.

This work is licensed under a Creative Commons Attribution-NonCommercial-NoDerivatives 4.0 International (CC BY-NC-ND 4.0) License. 